\title{
TESTING AND ANALYSIS OF THE IMPACT ON ENGINE CYCLE PARAMETERS AND CONTROL SYSTEM MODIFICATIONS USING HYDROGEN OR METHANE AS FUEL IN AN INDUSTRIAL GAS TURBINE
}

\author{
H. H.-W. Funke ${ }^{1}$, J. Keinz ${ }^{1}$, S. Börner ${ }^{1}$, P. Hendrick ${ }^{2}$, \\ and R. Elsing ${ }^{3}$ \\ ${ }^{1}$ Aachen University of Applied Sciences \\ 6 Hohenstaufenallee, Aachen 52064, Germany \\ ${ }^{2}$ Université Libre de Bruxelles \\ 50 Avenue F. D. Roosevelt, Bruxelles 1050, Belgium \\ ${ }^{3}$ Diehl Aerospace GmbH \\ 23 Alte Nußdorfer Str., Überlingen 88642, Germany
}

The paper highlights the modification of the engine control software of the hydrogen $\left(\mathrm{H}_{2}\right)$ converted gas turbine Auxiliary Power Unit (APU) GTCP 36-300 allowing safe and accurate methane $\left(\mathrm{CH}_{4}\right)$ operation achieved without mechanical changes of the metering unit. The acceleration and deceleration characteristics of the engine controller from idle to maximum load are analyzed comparing $\mathrm{H}_{2}$ and $\mathrm{CH}_{4}$. Also, the paper presents the influence on the thermodynamic cycle of gas turbine resulting from the different fuels supported by a gas turbine cycle simulation of $\mathrm{H}_{2}$ and $\mathrm{CH}_{4}$ using the software GasTurb.

\section{NOMENCLATURE}

\author{
APU auxiliary power unit \\ $\mathrm{CH}_{4}$ methane \\ $\mathrm{CO}$ carbon monoxide \\ $\mathrm{CO}_{2}$ carbon dioxide \\ $c_{p m}, \overline{\bar{c}}_{p}$ mean isobaric heat capacity \\ ECS environmental control supply \\ EGT exhaust gas temperature \\ $h \quad$ enthalpy
}

This is an Open Access article distributed under the terms of the Creative Commons Attribution License 4.0, which permits unrestricted use, distribution, and reproduction in any medium, provided the original work is properly cited. 
$H \quad$ humidity

$\mathrm{H}_{2} \quad$ hydrogen

IGV inlet guide vanes

LHV lower heating value

$\dot{m}$ mass flow rate

MES main engine start

$\mathrm{N}_{2}$ nitrogen

$\mathrm{O}_{2} \quad$ oxygen

$p \quad$ pressure

$P \quad$ power

$\dot{Q} \quad$ heat flow rate

SAR stoichiometric air requirement

$T$ temperature

UH unburned hydrogen

UHC unburned hydrocarbons $\left(\mathrm{C}_{x} \mathrm{H}_{y}\right)$

VECB versatile engine control box

$\Delta t \quad$ time index difference

$\eta_{T} \quad$ total efficiency

$\pi_{C} \quad$ compressor pressure ratio

$\tau_{t} \quad$ turbine temperature ratio

$\Phi \quad$ equivalence ratio

\section{Subscript}

0 station 0

3 station 3

4 station 4

$5 \quad$ station 5

air air-related

corr corrected

fuel fuel-related

$t$ total

$T$ turbine

\section{INTRODUCTION}

Aviation and power generation industry has need in efficient, reliable, safe, and low-pollution energy conversion systems in future. Gas turbines will play a decisive role in long-term high-power application scenarios, and hydrogen, hydrogenrich synthesis gases, and natural gas with high methane ratios have great potential as renewable and sustainable energy sources derived from wind- or solar power and gasification of biomass substituting the limited resources of fossil fuels [1]. These alternative fuels have important major impacts on the operation 
of common gas turbine systems. Especially hydrogen with its high reactivity requires combustion chamber modifications to guarantee efficient, stable, safe, and low NOx combustion regarding operational and environmental issues during operation. Besides optimized combustion technology and related exhaust gas emissions, modifications of the gas turbine control and fuel metering system have to be applied to guarantee safe, rapid, and precise changes of the engine power settings [2-7]. Against this background, the Gas Turbine Section of the Department of Aerospace Engineering at Aachen University of Applied Sciences works in the research field of low-emission combustion chamber technologies for hydrogen gas turbines and related topics and investigates the complete system integration of combustion chamber, fuel system, engine control software and emission reduction technologies. The current scope of research focuses on hydrogen and hydrogen-rich synthesis gases as future green and sustainable gas turbine fuels produced by renewables.

The paper demonstrates the conversion ability from liquid kerosene to gaseous alternative fuels. A formerly kerosene-driven hydrogen gas turbine is modified for methane operation. The operational characteristics of the kerosene gas turbine using hydrogen and methane are maintained without major modifications of the gas turbine structure and the control architecture. The transition from liquid to gaseous fuel has an important impact on the chosen control and fuel metering strategy of the gas turbine. The further adaption to methane requires only minor changes at the engine controller and the metering unit without any mechanical changes to the gas turbine.

\section{EXPERIMENTAL GAS TURBINE TEST RIG APU GTCP 36-300}

Aachen University of Applied Science uses an aircraft APU GTCP 36-300 as experimental test rig (Fig. 1). The GTCP 36-300 is a single-spool gas turbine with a single-stage radial compressor and a single-stage radial turbine. About 1.6 MW of thermal energy are converted to shaft power generating electrical and pneumatic power up to $335 \mathrm{~kW}$ provided by an auxiliary generator and an additional single-stage radial load compressor controlled by the Versatile Engine Control Box (VECB) built by Diehl Aerospace GmbH. The combustion section consists of an annular reverse flow combustion chamber with 6 circumferentially distributed fuel nozzles.

The APU is modified for operation with gaseous hydrogen and methane by replacing the genuine kerosene fuel nozzles with 6 nozzles for gaseous fuels and implementing a metering unit for gaseous fuels. An additional hydraulic system is installed to perform the hydraulic functions formerly operated with kerosene as hydraulic medium. 


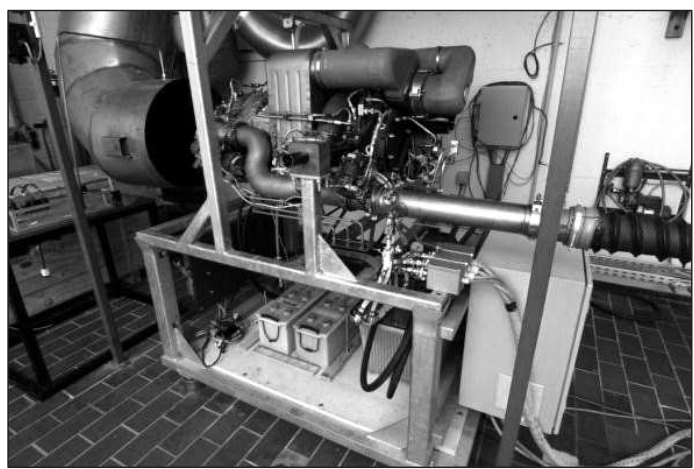

Figure 1 The APU GTCP 36-300 on test rig

The GTCP 36-300 has several load modes depending on the required electric or pneumatic demand of the aircraft. These modes can be separated into two main modes. The Environmental Control Supply (ECS) mode delivers compressed air for the aircraft air conditioning system; it is adjustable from idle to maximum ECS load. All ECS load stages operate at constant rotational speed of $99 \%$, the power output is controlled by movable Inlet Guide Vanes (IGV) which open or close depending on the particular power demands. The Main Engine Start (MES) mode delivers maximum electric and pneumatic power output required for the start procedure of the aircraft main engines; this mode runs on a constant rotational speed of $101 \%$.

Since the GTCP 36-300 is a rotational speed controlled gas turbine engine, the conversion to $\mathrm{H}_{2}$ and $\mathrm{CH}_{4}$ bases on the concept of always feeding the same requested amount of thermal heat into the combustion chamber maintaining

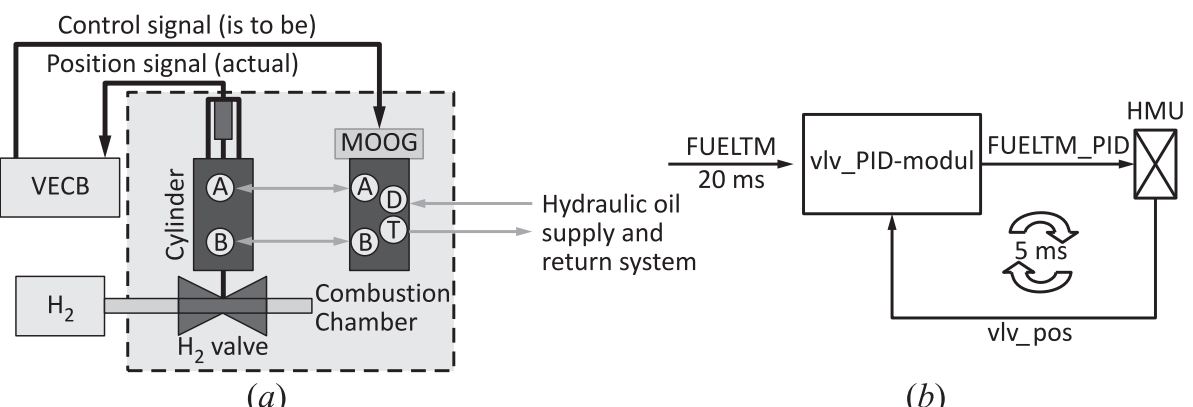

Figure 2 Metering unit for gaseous fuels $(a)$ and implemented metering unit control loop $(b)[5]$ 
the designated rotational speed for each load condition regardless which fuel is used. In [4-7], the successful implementation of a metering unit for gaseous fuels (Fig. 2), the modification of the fuel control system, and the reprogramming of the VECB (engine controller) for the use of hydrogen instead of kerosene are described. Reference [5] shows the start-up and acceleration behavior of the APU with hydrogen. Based on this experience, the paper presents the successful conversion of the APU from gaseous $\mathrm{H}_{2}$ to gaseous $\mathrm{CH}_{4}$. The control behavior at different loads and its acceleration and deceleration behavior with the installed nozzles for gaseous fuels without modifications of the fuel nozzles or any changes of the gas turbine mechanical structure and the combustion chamber are described.

\section{CONVERSION OF THE APU GTCP 36-300 FROM HYDROGEN TO METHANE}

\subsection{Adaption of the Gas Turbine Fuel Metering and Control}

Hydrogen and methane have a very different heating value, air requirement, flammability range, and flame speed. The change from $\mathrm{H}_{2}$ to $\mathrm{CH}_{4}$ has an impact on the combustion characteristics and the thermodynamic gas turbine cycle (refer section 4) influencing the engine control behavior. The lower heating value (LHV) of hydrogen is much higher. The same applies for the stoichiometric air requirement (SAR), while methane does not differ from kerosene in a great extent (refer Table 2). In consequence, two philosophies are possible when a keroseneAPU is converted to hydrogen and methane: $(i)$ hydrogen has lower combustion temperatures than kerosene, when equal heat flow rates are maintained; this can increase turbine hot parts lifetime, because the thermal load on these parts is decreased; and ( $i i)$ when the hydrogen operation is scaled to meet the same turbine inlet temperature or exhaust gas temperature (EGT) as with kerosene, considering the temperature limits of the turbine hot parts, the gas turbine power can be increased. The same applies for methane, but in a minor extend. In the current scope of work, the first approach is chosen.

The flammability range of hydrogen and methane poses a challenge in the fuel metering and control adaption at the gas turbine start-up. Hydrogen is flammable in the range of $4-75 \%$ (vol.) in air [8]; for methane, the range is only 4.4-15\%(vol.) in air [9]. As described in [6], the APU GTCP 36-300 with hydrogen is controlled by the VECB from Diehl Aerospace designed for kerosene. The adaption to gaseous fuels is done by software modifications only. These modifications enabled the original engine controller to control both the gas turbine and the metering unit for gaseous fuels by implementing an additional control loop for the metering unit. This avoids the need of additional and separate controller equipment for the metering unit for gaseous fuels. 
In Fig. 2, the setup of the metering unit and the additional control loop are illustrated. Every $20 \mathrm{~ms}$ the main engine controller sends the requested fuel flow (FUELTM) to the implemented metering unit controller (vlv-PID-Modul). Each amount of fuel is assigned to a certain valve opening position. The metering unit controller sends a control current (FUELTM_PID) to the MOOG-valve at the metering unit (HMU). The vlv_PID-Modul-controller operates the hydraulic MOOG-valve with a clocking of $5 \mathrm{~ms}$. By operating the MOOG-valve, the hydraulic cylinder traverses the $\mathrm{H}_{2}$ fuel valve to the requested position. The actual position of the fuel valve (vlv_pos) is measured by the positioning encoder and reported back to the controller. Besides the implementation of the additional control loop, security laws for the application of hydrogen are implemented [6] and maintained for methane operation.

The gas turbine is controlled by the main engine controller working according to two different philosophies: during the ignition and the starting sequence from $0 \%$ to $95 \%$ rotational speed, the engine is controlled by the start-upcontroller. At $95 \%$ speed, the on-speed-governor takes over. The on-speedgovernor controls the engine operational behavior and keeps the rotational speed constant depending on the selected mode: $99 \%$ speed for all ECS load stages and $101 \%$ speed for MES by varying the fuel quantity depending on the selected load stage. While the behavior of the on-speed-governor is the same for kerosene, hydrogen, and methane operation, the acceleration controller is to be modified for methane operation.

At first, it is necessary to determine the required fuel mass flow of methane considering equal thermal heat flow rates in the combustion chamber compared to hydrogen:

$$
\dot{Q}_{\mathrm{CH}_{4}}=\dot{Q}_{\mathrm{H}_{2}} \text {. }
$$

This leads to the basic calculation of the required methane mass flow, which is about 2.4 times higher than the required hydrogen mass flow (also, refer Table 2) what will certainly have an influence on the controller behavior:

$$
\dot{m}_{\mathrm{CH}_{4}}=\dot{m}_{\mathrm{H}_{2}} \frac{\mathrm{LHV}_{\mathrm{H}_{2}}}{\mathrm{LHV}_{\mathrm{CH}_{4}}}=\dot{m}_{\mathrm{H}_{2}} \frac{119.95}{50.03}=2.4 \dot{m}_{\mathrm{H}_{2}} .
$$

The start-up-controller uses a function of speed for the fuel metering during the starting process. A valve opening position is related to a defined fuel flow and attributed to several decided speed steps during the acceleration up to $95 \%$ rotational speed. Between two speed steps, the controller interpolates the valve opening position [5]. According to the described differences, the speed step FUELTM values of hydrogen implemented in the controller must be transferred into FUELTM values for the methane acceleration process considering equal heat flow rates. The initial control current FUELTM_PID in the control loop is increased to take into account the lower LHV of methane assuring enough fuel flow at speeds below $30 \%$ for the initial acceleration (fuel spiking). Additionally, 
the initial speed step in the start-up controller is shifted to an earlier rotational speed to ensure a safe ignition with an increased fuel flow considering the heating value and the narrow flammability limits of methane.

With these minor modifications in the start-up-controller, the acceleration can be realized without difficulties, the changeover from the start-up-controller to the on-speed-governor at $95 \%$ rotational speed is ensured and the gas turbine accelerates to $99 \%$ constant rotational idle speed. No modifications of the onspeed-governor PID-parameters are performed, the PID-parameters of hydrogen operation are maintained. In [5,7], the ignition and acceleration characteristics of the hydrogen operated APU GTCP 36-300 are described in detail.

\subsection{Engine Operational Behavior at Acceleration Idle-MES and Deceleration MES-Idle}

After establishing stable and secure idle operation of the gas turbine, especially the acceleration and deceleration characteristics of the engine controller behavior from idle to maximum load operation mode (MES) comparing hydrogen and methane are of interest. Figure 3 shows the measured results of the rotational speed and setting of the MES load condition by means of the IGV position during the acceleration from idle to MES and the deceleration from MES back to idle. The rotational speed is depicted on the left axis in percent of the maximum speed; the IGV position is described as the guide vane angle on the right axis; on the abscissa, the time is applied by means of a dimensionless time index.

The load change to MES is initiated by switching the IGV position from about $20^{\circ}$ to $80^{\circ}$ with a simultaneous boost in the rotational speed from $99 \%$ to $101 \%$ increasing the bleed air flow in the pneumatic system for the main engine start. The adjustment of the IGV angle for either the acceleration or the deceleration is identical for both hydrogen and methane operations which results in a comparable load change. For the adjustment of the rotational speed, a different effect is observed. Changing from idle to MES, the on-speed-governor controls the rotational speed to $101 \%$ for both fuels after a slight overshoot. While the setting of constant $101 \%$ speed is rather fast for hydrogen, the controller takes longer to establish $101 \%$ speed when using methane as fuel. A similar effect is observed analyzing the change from MES back to idle. Again, the adjustment time for the IGV positioning is the same for both fuels. When the deceleration process is initiated by the sudden switch-off of the load, the rotational speed at hydrogen operation overshoots to $101.85 \%$; the speed in methane operation overshoots even to $102.20 \%$. After a short time delay in the controller, the speed is readjusting to constant $99 \%$ idle; in methane operation, the time delay again is bigger than in hydrogen operation.

The reason of the differing behavior in acceleration and deceleration between methane and hydrogen is found when the moving characteristics of the fuel valve at the metering unit for gaseous fuels are analyzed in Fig. 4, where the relative 

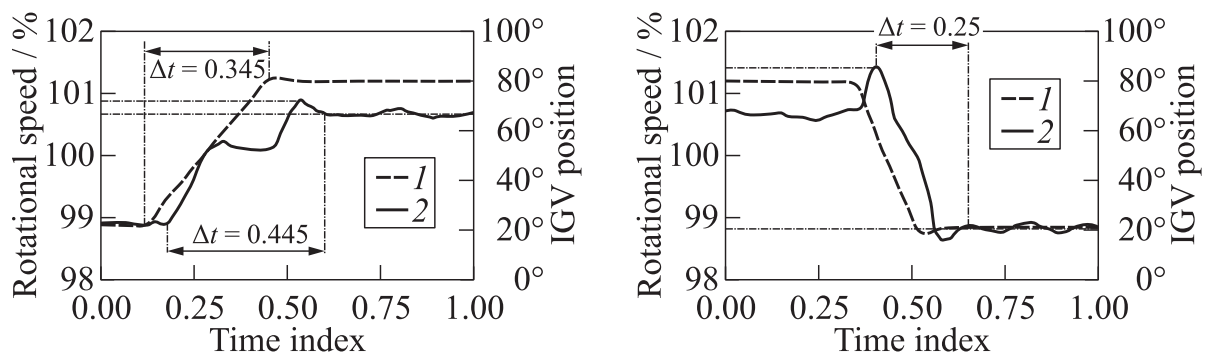

(a)
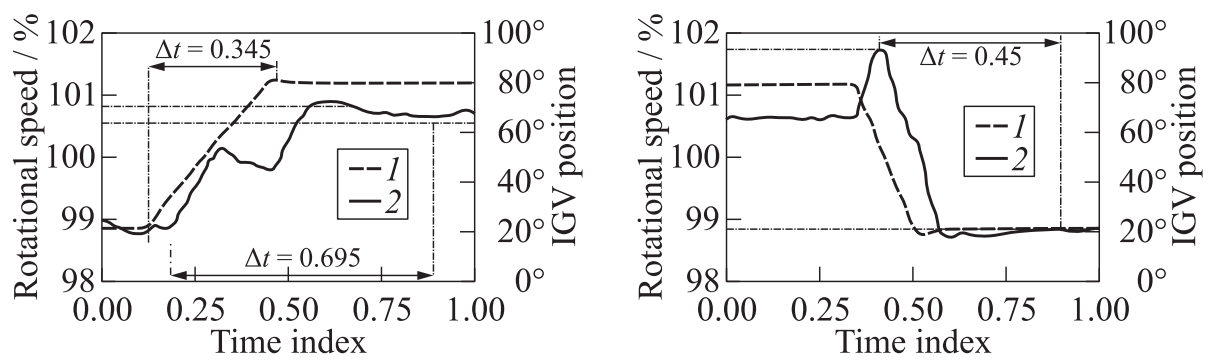

(b)

Figure 3 Acceleration and deceleration behavior of the engine controller for MES of hydrogen $(a)$ and methane $(b)$ : left column - MES ON; right column - MES OFF; 1 - IGV; and 2 - rotational speed

way of opening and closing of the fuel valve each for hydrogen and methane is depicted vs. the same time index scaling as in Fig. 3.

In Fig. $4 a$, the relative fuel valve opening at the acceleration from $99 \%$ idle to $101 \%$ MES is shown. While the traverse path of the valve is relatively small for hydrogen, the on-speed-governor opens the valve much wider for methane when MES mode is initiated with the applied controller settings similar to hydrogen. This initial opening command from the on-speed-governor moves the valve very fast up into its maximum mechanical opening position. A similar effect is due to the deceleration in Fig. $4 b$. The on-speed-governor initiates the valve closing according to the implemented and maintained control parameters from hydrogen. Again, the adjustment is very fast and too excessive and the valve is closed in a much greater extend as required to reach idle forcing the governor to readjust back to the required methane flow.

Despite these small differences, always and with either fuel the acceleration and deceleration of the gas turbine load change is completed safely and reliably. In fact, with minor differences in the controller behavior, the same control settings with slight modifications in the start-up-process and the common metering unit architecture enable a successful starting sequence and operation of 


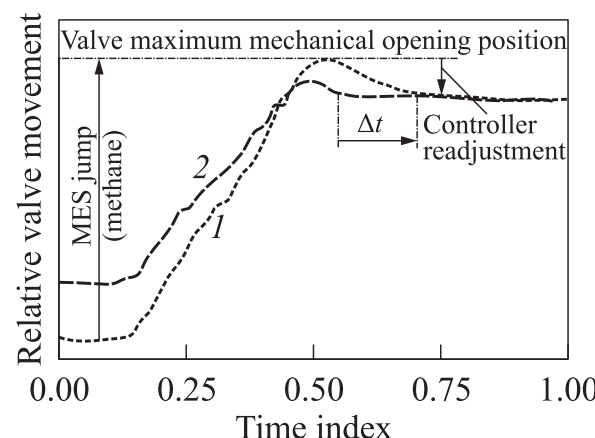

(a)

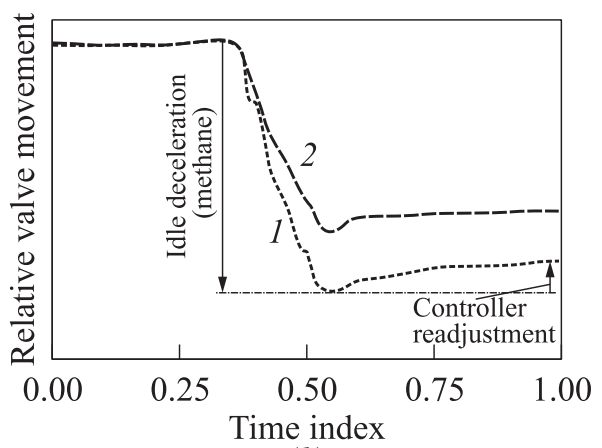

(b)

Figure 4 Metering unit fuel valve movement during acceleration (MES ON) (a) and deceleration (MES OFF) (b): $1-\mathrm{CH}_{4}$; and $2-\mathrm{H}_{2}$

the gas turbine with both hydrogen and methane. The engine controller is able to safely and reliably initiate load changes and shows acceptable performance in a dual-fuel hydrogen/methane gas turbine application.

\section{ANALYSIS OF GAS TURBINE THERMODYNAMIC CYCLE WITH HYDROGEN AND METHANE}

\subsection{APU Performance Model}

A change of fuel influences the thermodynamic cycle of the gas turbine $[10,11]$. Besides starting procedure and control of the gas turbine, fuel mass flow, equivalence ratio, combustion and turbine inlet temperature, compressor pressure ratio and, thereby, the characteristics of compressor and turbine, and EGT are influenced. The presented experimental investigation is completed by a theoretical analysis of the thermodynamic cycle supported by a gas turbine cycle simulation using the software GasTurb [12]. The GasTurb-performance-model of the APU GTCP 36-300 is created regarding the recommendations for performance models of gas turbines from [13], the adjustment of component maps for performance calculations in [14], and the correction of model based on gas turbine parameters from [15]. The applied performance model of the APU GTCP 36-300 used at Aachen University of Applied Sciences is already validated for kerosene operation against detailed experimental performance test data from the APU manufacturer. This existing performance model is used as basis to analyze the impact on the thermodynamic cycle of the APU fuelled with hydrogen and methane. The used nomenclature in the following sections to describe some effects is similar to the gas turbine station description from GasTurb shown in Fig. 5. 


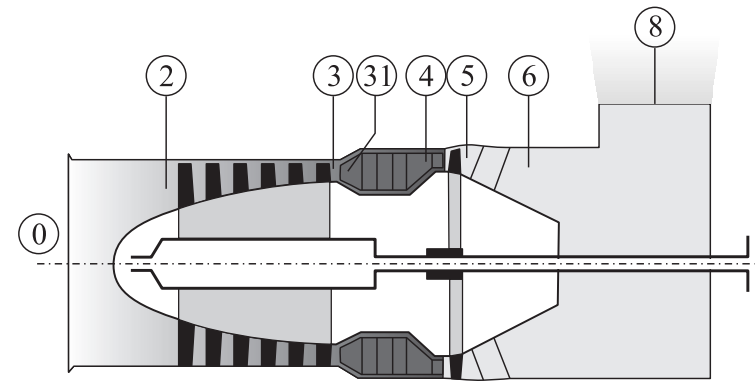

Figure 5 Station description of turbo shaft gas turbine [12]: Station: 0 - ambient surrounding / air inlet; 2 - compressor inlet; 3 - compressor outlet; 31 - combustion chamber inlet (applied estimation: station $3=$ station 31); 4 - combustion chamber outlet; 5 - turbine outlet; 6 - exhaust nozzle cone outlet; and 8 - exhaust outlet to ambient surrounding

The stations most important for the analysis presented in this work are:

- Station 0: measurement of the ambient surrounding air conditions pressure, temperature, and humidity; important for correction calculations of parameters to International Standard Atmosphere (ISA) conditions;

- Station 4: analysis of the combustion conditions and turbine inlet conditions, respectively; and

- Station 5: measurement of the exhaust gas conditions.

The required data for the analysis are obtained by several sensors. The ambient conditions of pressure $p_{0}$, temperature $T_{0}$, and relative humidity $H_{0}$ are measured with an Ahlborn Almemo 8390-2 system at the gas turbine air inlet. To determine the parameters in the combustion chamber at station 4 , exhaust gas samples are drawn for analysis. The extraction of the sample, the design of the probe, and the heating of probe and tubing must be sophisticated considered, when samples are drawn for chemical analysis from the exhaust gases. Concentration changes of the different components within the exhaust gas sample must be avoided; condensation of water and unburned hydrocarbons in the tubing influences the analysis results. An appropriate sampling system should consider typical conditions like sample flow rate and velocity influencing probe and tubing size, condensation temperatures of typical exhaust gas components, pressure drop through the system, etc. A proper design of the sampling system ensures exhaust gas samples with representative concentrations of the constituents. To take into account all these sampling requirements, the APU GTCP 36-300 test rig is equipped with a heated rotating isokinetic probe to extract representative isokinetic exhaust gas samples covering the complete flow area of the exhaust gas jet. 
Table 1 Description of analysis system devices, measuring ranges, and accuracies

\begin{tabular}{llll}
\hline \multicolumn{1}{c}{ Device } & \multicolumn{1}{c}{ Component } & \multicolumn{1}{c}{ Range } & Accuracy \\
\hline Ahlborn Almemo & Ambient pressure $p_{0}$ & $700-1050 \mathrm{mbar}$ & $\pm 0.5 \%$ \\
8390-2 Universal & Ambient temperature $T_{0}$ & $0-70{ }^{\circ} \mathrm{C}$ & $\pm 0.1{ }^{\circ} \mathrm{C}$ \\
Measuring System & Ambient humidity $H_{0}$ & $0-100 \%$ (r.H.) & $\pm 2 \%$ r.H. \\
\hline ABB Multi FID 14 & $\mathrm{C}_{x} \mathrm{H}_{y}$ & $0-25000 \mathrm{ppm}$ & $\leq 2 \%$ \\
\hline ABB Caldos 27 & $\mathrm{H}_{2}$ & $0-4 \%$ (vol.) & $\leq 2 \%$ \\
\hline ABB URAS 26 & $\mathrm{CO}$ & $0-100000 \mathrm{ppm}$ & \multicolumn{1}{c}{$1 \%$} \\
& $\mathrm{CO}_{2}$ & $0-15 \%($ vol.) & $\leq$ \\
\hline ABB MAGNOS 206 & $\mathrm{O}_{2}$ & $0-50 \%(\mathrm{vol})$. & $\leq 0.5 \%$ \\
\hline Div. thermocouples & Relative temperature conditions & $0-800{ }^{\circ} \mathrm{C}$ & $\pm 0.25 \%$ \\
\hline MicroMotion CMF050 & Fuel mass flow & $1526 \mathrm{~N} \cdot \mathrm{m}^{3} / \mathrm{h}$ & $\pm 0.35 \%$ \\
\hline
\end{tabular}

The gas sample is directed to each analyzed module by heated tubes and hoses under controlled pressure conditions in the ductwork. A state-of-the-art exhaust gas analysis system is used to determine the amount of unburned hydrocarbons (ABB Multi FID 14) and unburned hydrogen (ABB Caldos 27), the quantity of $\mathrm{CO}$ and $\mathrm{CO}_{2}$ (ABB URAS 26), and the concentration of $\mathrm{O}_{2}$ (ABB Magnos 206). The total temperature $T_{5 t}$ at the turbine outlet is measured by the gas turbine thermocouples and an additionally installed fast thermocouple connected to the test stand analysis system. The fuel mass flow of hydrogen and methane is obtained by a MicroMotion CMF050 massflowmeter and the power output of the APU is determined by an orifice measurement of the pneumatic bleed air output according to EN ISO 5167. A generator for electric power production is not installed in the APU. Since the bleed air power is directly proportional to the shaft power, it is used to determine the total gas turbine power output. The measuring devices and their measuring ranges and accuracies are summarized in Table 1.

In Fig. 6, the results from performance calculations and experimental analysis data are presented showing the required fuel mass flow for several load conditions (Fig. $6 a$ ) and the increase of temperature in the combustion chamber $\left(T_{4 t}-T_{3 t}\right)$ in Fig $6 b$ depicted vs. the equivalence ratio $\Phi$ in the combustion chamber. In Fig. 7, the corrected EGT at the turbine exit $T_{5 t}$ is depicted over the corrected shaft power output. All diagrams compare calculated data from the performance model with experimental data gathered by independent analyzing systems (MicroMotion fuel meter, exhaust gas analysis system, restrictor measurement, and thermocouple measurements). The measurement data and the GasTurb calculations show very good agreement and, thereby, validate the performance model of the APU for hydrogen and methane derived from the genuine kerosene model allowing detailed analyses of the gas turbine cycle. Since there are always unconformities in the exhaust gas which cannot be covered 


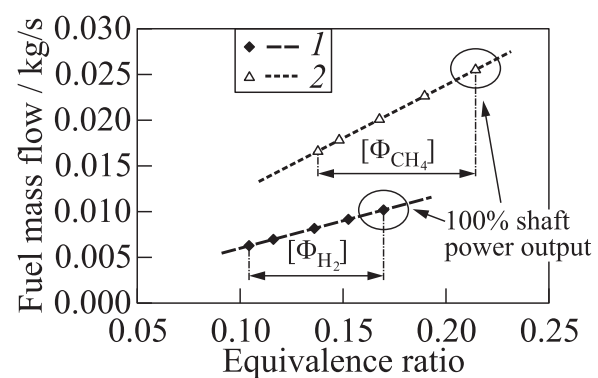

(a)

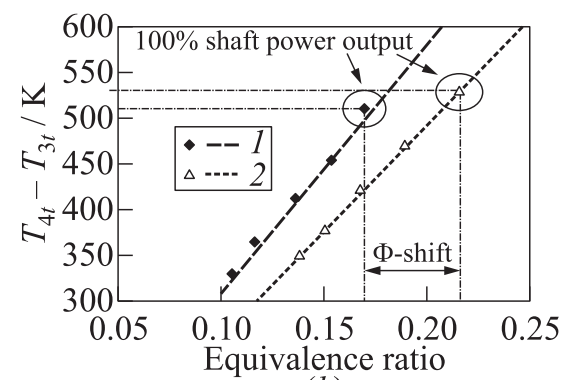

(b)

Figure 6 Fuel mass flow $(a)$ and temperature increase in the combustion chamber $(b)$ : $1-\mathrm{H}_{2}$; and $2-\mathrm{CH}_{4}$. Signs refer to experiments and lines to GasTurb calculations

by the applied temperature measuring method with equally distributed thermocouples on the exhaust nozzle circumference, the grey shaded area in Fig. 7 illustrates an unconformity scatter of the temperature distribution. It can be seen that in the higher power areas (80\%-100\%), measurements and calculations are accurate while in the upper part load section $(60 \%)$, the values are within the unconformity scatter; only in the low power area $(<40 \%)$, the measurement data does not fit into the scatter. The performance model in GasTurb is validated for reliable manufacturer data for kerosene for high power operation. The part load section is extrapolated from the high power data and scaled compressor and turbine maps from GasTurb are used. In the relevant area of $80 \%-100 \%$ power output discussed in this paper, the model and the measuring data have a high reliability and reproducibility to allow profound analyses.

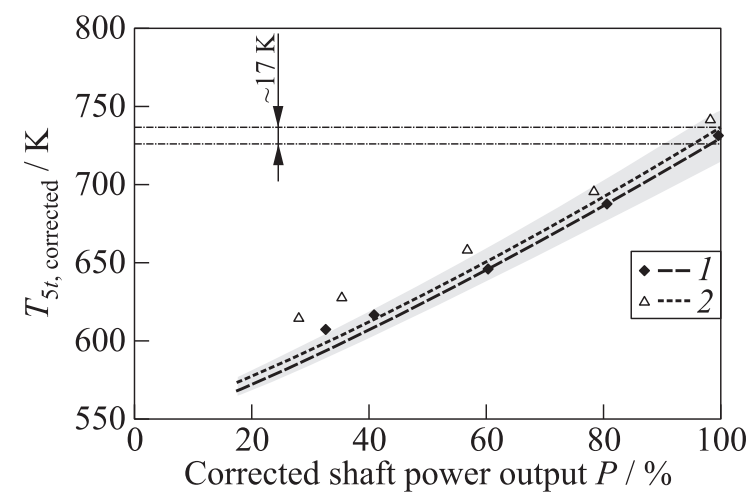

Figure 7 Corrected EGT: $1-\mathrm{H}_{2}$; and $2-\mathrm{CH}_{4}$. Signs refer to experiments and lines to GasTurb calculations 


\subsection{Influences on the Gas Turbine Cycle}

Figure $6 b$ highlights that changing from hydrogen to methane results in a shift of the equivalence ratio range in the gas turbine combustion chamber while the same shaft power output is maintained. Referring to Eqs. (1) and (2), scaling with equal heat flow rate and therewith equal shaft power lead to a change in the required fuel mass flow and a subsequent shift in the equivalence ratio:

$$
\Phi_{\mathrm{CH}_{4}}=\Phi_{\mathrm{H}_{2}} \frac{\mathrm{LHV}_{\mathrm{H}_{2}}}{\mathrm{LHV}_{\mathrm{CH}_{4}}} \frac{\mathrm{SAR}_{\mathrm{CH}_{4}}}{\mathrm{SAR}_{\mathrm{H}_{2}}} .
$$

Figure 6 also shows the shift to a more rich equivalence ratio range interval for methane resulting from the influence of the fuel lower heating value LHV and the impact of the stoichiometric air requirement SAR at similar heat flow rates and shaft power output. Since all relevant parameters are known (Table 2) the equivalence ratio shift can be calculated:

$$
\Phi_{\text {fuel }}=\frac{\dot{m}_{\text {fuel }} \mathrm{SAR}_{\text {fuel }}}{\dot{m}_{\text {air }}}=\frac{\dot{Q}}{\dot{m}_{\text {air }}} \frac{\mathrm{SAR}_{\text {fuel }}}{\mathrm{LHV}_{\text {fuel }}} .
$$

In the case of the APU, the coefficient $\left(\dot{Q} / \dot{m}_{\text {air }}\right)$ can be considered as nearly constant. Therefore, the equivalence ratio $\Phi$ is proportional to the ratio of the stoichiometric air requirement SAR divided by the lower heating value LHV:

$$
\Phi \propto \frac{\mathrm{SAR}_{\text {fuel }}}{\mathrm{LHV}_{\text {fuel }}} .
$$

The determined ratios and the equivalence ratio shift of methane and hydrogen against kerosene are compared in Table 2 . The result of the equivalence ratio shift shows that the equivalence ratio of hydrogen is about $16.7 \%$ leaner compared to kerosene while methane remains in nearly identical order to kerosene, but is slightly richer.

Figure 7 shows that between methane and hydrogen, there is an offset in the EGT. The EGT of methane is higher compared to the EGT of hydrogen by about $17 \mathrm{~K}$ at $100 \%$ shaft power. Comparing Figs. 6 and 7, the richer fuel

Table 2 Properties of hydrogen, kerosene and methane, equivalence ratio shift relative to kerosene [16-18]

\begin{tabular}{lccccc}
\hline \multicolumn{1}{c}{ Component } & $\begin{array}{c}\mathrm{SAR}_{\text {fuel }}, \\
\mathrm{kg}_{\text {Air }} / \mathrm{kg}_{\text {fuel }}\end{array}$ & $\begin{array}{c}\mathrm{LHV} \text { fuel } \\
\mathrm{MJ} / \mathrm{kg}\end{array}$ & $\begin{array}{c}\mathrm{SAR}_{\text {fuel }} \\
\mathrm{LHV}_{\text {fuel }}\end{array}$ & $\Phi$-shift & $\Phi$-shift, \% \\
\hline Hydrogen, $\left(\mathrm{H}_{2}\right)$ & 34.3 & 119.95 & 0.2860 & 0.8326 & -16.74 \\
Kerosene $\left(\mathrm{Jet}_{\mathrm{A}} \mathrm{A}-1\right)$ & 14.7 & 42.80 & 0.3435 & 1.0000 & 0 \\
Methane $\left(\mathrm{CH}_{4}\right)$ & 17.2 & 50.03 & 0.3438 & 1.0009 & +0.09 \\
\hline
\end{tabular}




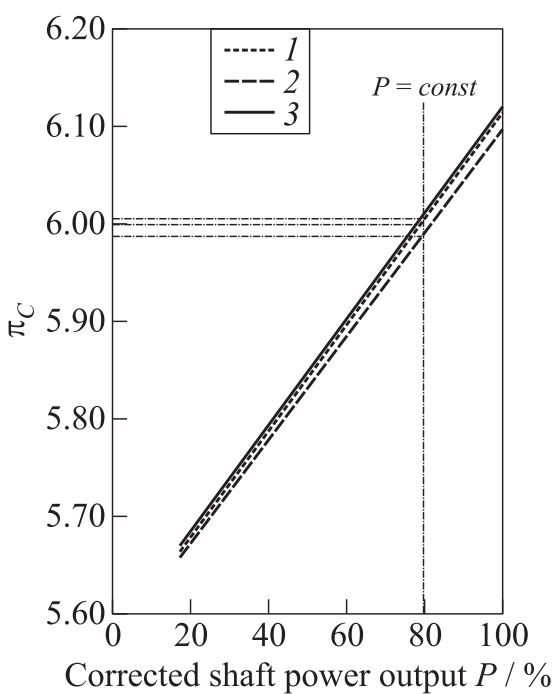

Figure 8 Compressor pressure ratio: $1-\mathrm{CH}_{4} ; 2-\mathrm{H}_{2}$; and $3-$ kerosene mixture at methane operation and the leaner mixture at hydrogen operation resulting from the $\Phi$-shift lead to different combustion temperatures changing the EGT on the turbine exit and, surely, will have effects on the operational point of the gas turbine.

In Fig. 8, the compressor pressure ratio $\pi_{C}$ is depicted vs. the corrected shaft power output $P$ of kerosene, methane, and hydrogen. It can be observed that for a constant shaft power, the pressure ratio of the compressor changes for different fuels. In Fig. 9, the compressor characteristics are shown schematically for constant power. The APU GTCP 36-300 is a rotational speed controlled gas turbine running on constant $99 \%$ rotational speed for all ECS load conditions and on constant $101 \%$ speed in MES mode

independent from the used fuel. The schematic presents that the operational point at constant power is shifted downwards along the line of operation with constant speed from kerosene over methane to hydrogen and show that the characteristics of the compressor, i.e., the compressor pressure ratio and the air mass flow through the compressor, must change. Two different effects must be considered here:

(1) when the operational point of the gas turbine changes along the line of constant speed in the compressor map, the efficiency and the performance requirements of the turbine change, too. Since the compressor pressure ratio $\pi_{C}$ is influenced, the total efficiency $\eta_{t}$ of the gas turbine cycle is also slightly affected, i.e., when $\pi_{C}$ decreases, $\eta_{t}$ decreases. Simultaneously, the air mass flow $\dot{m}_{\text {air }}$ increases and results in a shift of the specific enthalpy ratio. It can be stated that the shift in the cycle operation point is influenced mostly by the change in combustion temperature $T_{4 t}$; and

(2) the cycle operational point is influenced by the different required fuel mass flows for kerosene, methane, and hydrogen. The turbine power is reduced with decreasing fuel mass flow $\dot{m}_{\text {fuel }}$ and must be compensated in an increase of the enthalpy $\Delta h_{T}$ :

$$
P_{t} \approx\left(\dot{m}_{\text {air }}+\dot{m}_{\text {fuel }}\right) \Delta h_{T} .
$$


Figure 9 shows that the shift along the operational line in the compressor map for hydrogen, methane, and kerosene is influenced by the combustion temperature $T_{4 t}$. Each kerosene, methane, and hydrogen generates different combustion temperatures changing the operational point and the efficiency in the turbine. Generally, the influences on the efficiency of the turbine and the cycle are minor, the interaction between $T_{4 t}$ and $c_{p m}\left(\overline{\bar{c}}_{p}\right)$ are the dominant drivers for this phenomenon. The enthalpy in the turbine is

$$
\Delta h_{T} \approx \overline{\bar{c}}_{p} T_{4 t}\left(1-\tau_{t}\right) .
$$

Figure 10 points out the differences in the combustion temperature $T_{4 t}$. In the figure, the difference $\Delta T_{4 t}$ between methane and kerosene and the difference between hydrogen and kerosene is presented calculated by GasTurb. At constant 100\% power,

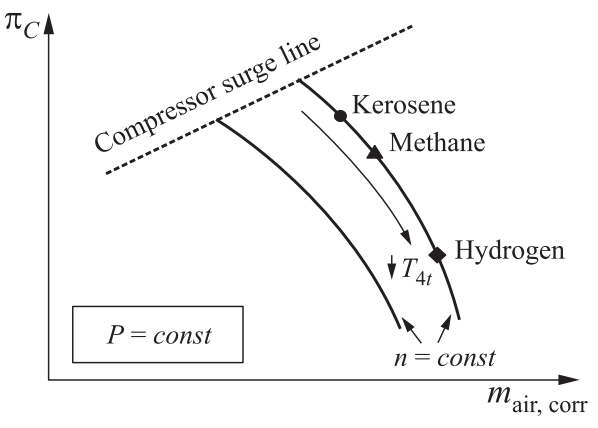

Figure 9 Schematic compressor map $T_{4 t}$ of methane is about $7 \mathrm{~K}$ lower as the combustion temperature of kerosene. For hydrogen compared to kerosene, the difference is even about $18 \mathrm{~K}$ lower matching the theory of Fig. 9. In Fig. 10b, the combustion temperature $T_{4 t}$ is shown in relation to the equivalence ratio. Comparing Figs. $10 a$ and $10 b$, it can be observed that the differences of $T_{4 t}$ both of methane and hydrogen related to kerosene are not the same. Figure $10 a$ shows the combustion temperature difference including the effect of the $\Phi$-shift and the subsequent combustion temperature $T_{4 t}=f(\Phi)$. In Fig. 10b, the temperature effect alone is depicted. It can be seen that at a constant equivalence ratio, hydrogen burns much hotter than methane. The $\Phi$-shift

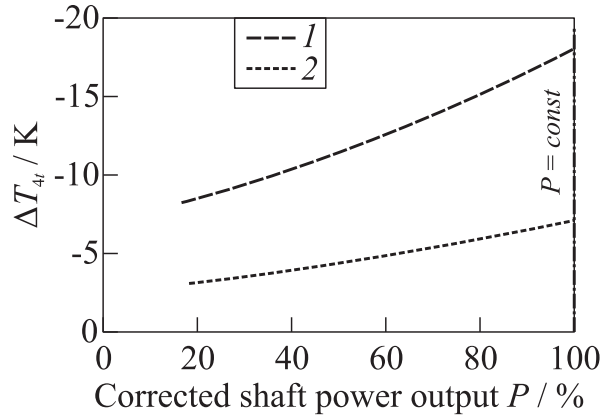

(a)

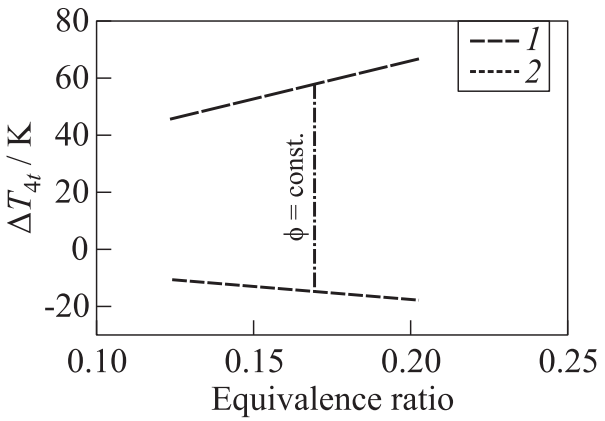

(b)

Figure 10 Combustion temperature difference related to kerosene calculated with GasTurb: 1 - methane-kerosene; and 2 - hydrogen-kerosene 


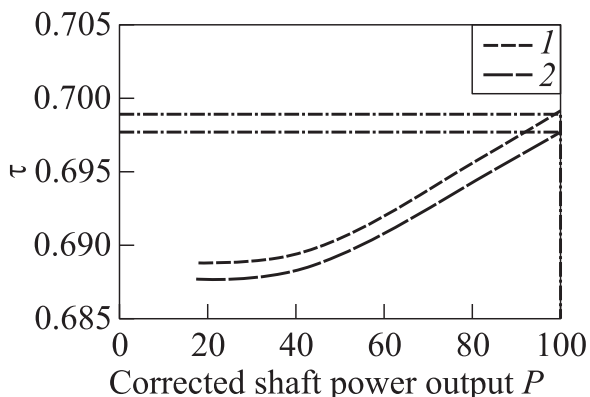

(a)

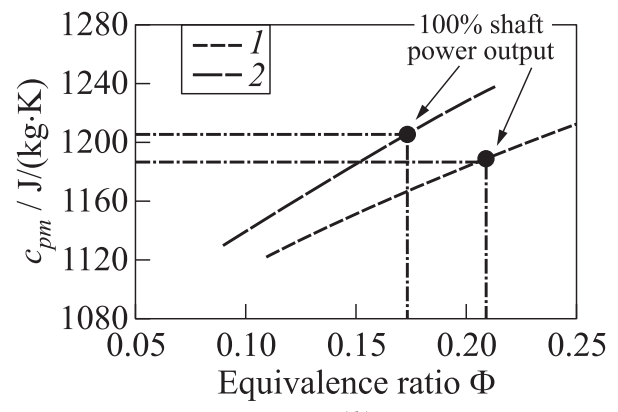

(b)

Figure 11 Turbine temperature ratio $(a)$ and isobaric heat capacity $(b): 1-\mathrm{CH}_{4}$; and $2-\mathrm{H}_{2}$

leads to the effect that in the gas turbine, in fact, the hydrogen burns colder than kerosene and methane confirming the theory of Fig. 8.

Regarding the $T_{4 t}$-effect, a decrease leads to a lower turbine performance, but Fig. $10 a$ shows that $100 \%$ shaft power are maintained. Besides, the combustion temperature, the impact of the mean isobaric heat capacity $c_{p m}$, and the turbine temperature ratio $\tau_{t}=T_{5 t} / T_{4 t}$ should be considered. Comparing the $100 \%$ shaft power output point in Fig. 11, the diagram shows that $\tau_{t}$ of hydrogen is lower than the $\tau_{t}$ of methane. The mean isobaric heat capacity $c_{p m}$ is depending on the equivalence ratio at the $100 \%$ power point. For hydrogen, $c_{p m}$ at $100 \%$ power is higher than $c_{p m}$ of methane. For the hydrogen operation, the higher $c_{p m}$ combined with the reduced $\tau_{t}$ for hydrogen both have positive effects on the turbine enthalpy maintaining turbine power for $100 \%$ shaft power output together with a reduced fuel flow.

It can be stated that for hydrogen, the impact of $\tau_{t}$ and $c_{p m}$ is dominant while for methane, the $T_{4 t}$-temperature effect is most significant.

Another effect should be also considered for $\tau_{t}$. Figure $10 a$ shows that methane and hydrogen both have a lower combustion temperature compared to kerosene at constant power. As described earlier, the power of a gas turbine could be increased by scaling the combustion temperature (turbine inlet temperature) equal to kerosene generating more power and matching the same turbine inlet conditions. But as a result of the turbine temperature ratio $\tau_{t}$, it should be considered that the parts at the turbine exit are charged by higher temperatures as normal leading to life time reduction or even failure. Scaling to the same EGT $T_{5 t}$, the effect remains the same, but the influence is different and while the parts at the turbine exit are normally charged, the area at the turbine inlet is affected by excessive heat. An increase in power of an existing gas turbine by the change of fuel with a higher heating value is possible, but sensitive considerations and modifications of the turbine cooling system should be taken into account. 
The presented theoretical investigation of the gas turbine cycle supported by GasTurb shows that the change of fuel has significant impact on the gas turbine. The fuel properties influence the fuel-air mixture in the combustion chamber and lead to an equivalence ratio shift and different combustion temperatures. This affects the operational point of the gas turbine at constant power because the compressor and turbine characteristics are changed. The balance between the combustion temperature, the mean isobaric heat capacity, and the turbine temperature ratio influences turbine characteristics and also the EGT level while the turbine power remains almost constant. This has an impact on the control strategy of the gas turbine when EGT control is applied, but the benefit of possible increased gas turbine power switching from kerosene to methane and hydrogen arises.

\section{CONCLUDING REMARKS}

It is possible to convert a gas turbine for the use of gaseous fuels and to operate it alternatively with hydrogen and methane. For alternating dual-fuel-operation, no mechanical changes of the gas turbine are required, only slight modifications of the start-up-controller software are necessary regarding ignition and initial acceleration. In a future scope of work, the gas turbine main engine controller can be optimized by improving the on-speed-governor for the dual-fuel operation with hydrogen and methane implementing adaptable control parameters when switching between fuels.

The theoretical investigation of the thermodynamic cycle shows that the change of fuel has a significant impact on the gas turbine operation point. An equivalence ratio shift occurs and affects the combustion temperature at constant gas turbine power changing the characteristics of compressor and turbine.

Additionally, hydrogen gives the opportunity to increase the power output of an existing gas turbine at equal EGTs like kerosene or methane, but the influences of different behavior in the turbine temperature ratio should be considered to avoid overheating of turbine parts. Another interesting aspect is that when changing a gas turbine from kerosene or methane to hydrogen, hydrogen burns at lower temperatures while the same gas turbine power output level is preserved. This leads to the opportunity to increase the turbine section hot parts life time, because the prevailing temperatures at the turbine inlet are reduced.

\section{REFERENCES}

1. Lieuwen, T., V. Yang, and R. Yetter, eds. 2009. Synthesis gas combustion: Fundamentals and applications. Boca Raton-London-New York: CRC Press. 400 p.

2. Suttrop, F., and R. Dorneiski. 1991. Low NOx-potential of hydrogen-fuelled gas turbine engines. 1st Conference (International) on Combustion Technologies for a Clean Environment. Vilamoura, Portugal. 
3. Dahl, G., and F. Suttrop. 1998. Engine control and low-NOx combustion for hydrogen fuelled aircraft gas turbines. Int. J. Hydrogen Energy 23:695-704.

4. Funke, H.H.-W., S. Börner, P. Hendrick, and E. Recker. 2011. Modification and testing of an engine and fuel control system for a hydrogen fuelled gas turbine. Progress in propulsion physics. Eds. L. DeLuca, C. Bonnal, O. Haidn, and S. Frolov. EUCASS advances in aerospace sciences book ser. 2:475-486.

5. Funke, H.H.-W., S. Börner, P. Hendrick, and E. Recker. 2010. Control system modifications for a hydrogen fuelled gas-turbine. 13th Symposium (International) on Transport Phenomena and Dynamics of Rotating Machinery (ISROMAC13).

6. Funke, H. H.-W., S. Börner, P. Hendrick, E. Recker, and R. Elsing. 2011. Development and integration of a scalable low NOx combustion chamber for a hydrogen fuelled aero gas turbine. 4th European Conference for Aeronautics and Space Sciences (EUCASS). St. Petersburg.

7. Börner, S., H. H.-W. Funke, F. Falk, and P. Hendrick. 2011. Control system modifications and their effects on the operation of a hydrogen-fueled Auxiliary Power Unit. 20th Symposium (International) on Air Breathing Engines (ISABE 2011).

8. Westfalen AG. 2015. Hydrogen — safety data sheet.

9. Westfalen AG. 2015. Methane - safety data sheet.

10. Chiesa, P., G. Lozza, and L. Mazzocchi. 2005. Using hydrogen as gas turbine fuel. Trans. ASME J. Eng. Gas Turbines Power 127(1):73-81.

11. Verstraete, D., P. Hendrick, P. Pilidis, and K. Ramsden. 2005. Hydrogen as an (aero) gas turbine fuel. 17th Symposium (International) on Air Breathing Engines (ISABE 2005).

12. Kurzke, J. 2007. GasTurb: Design and off-design performance of gas turbines. Software Manual. http://www.gasturb.de/manual.html (accessed October 30, 2015).

13. Kurzke, J. 2005. How to create a performance model of a gas turbine from a limited amount of information. ASME Turbo Expo 2005: Power for Land, Sea and Air Proceedings. American Society of Machanical Engineers. 145-153.

14. Kurzke, J. 1996. How to get component maps for aircraft gas turbine performance calculations. International Gas Turbine and Aeroengine Congress \& Exhibition of the American Society of Mechanical Engineering Proceedings. American Society of Machanical Engineers. V005T16A001-V005T16A001.

15. Kurzke, J. 2003. Model based gas turbine parameter corrections. ASME Turbo Expo 2003 collocated with the 2003 Joint Power Generation Conference (International) Proceedings. American Society of Machanical Engineers. 91-99.

16. Deutsches Institut für Normung e.V. 1997. Berechnung von Brennwert, Heizwert, Dichte, relativer Dichte und Wobbeindex von Gasen und Gasgemischen. DIN 51857:1997-03.

17. Exxon Mobil Aviation. 2008. World jet fuel specifications with avgas supplement. Machelon: ExxonMobil Aviation. Available at: http://www.exxonmobil.com/ AviationGlobal/Files/WorldJetFuelSpec2008_1.pdf. (accessed October 30, 2015).

18. Esch, Th. 2011. Verbrennungstechnik - combustion technology: Textbook. 8th ed. Aachen: Department of Aerospace Engineering, Aachen University of Applied Sciences. Unpubl. 